\title{
Journal of Bacteriology and

\section{Prevalence of Listeria monocytogenes and Salmonella spp. in Ready-to-Eat Foods in Kefalonia, Greece}

\section{Eriotou Effimia}

Department of Food Technology, Technological Educational Institute (T.E.I.) of Ionian Islands, Terma Leoforou Vergoti, 28100 Kefalonia, Greece

*Corresponding author: Eriotou Effimia, Department of Food Technology, Technological Educational Institute (T.E.I.) of Ionian Islands, Terma Leoforou Vergoti, 28100 Kefalonia, Greece, Tel: +0030-26710-27101; Fax: +0030-26710-27102; E-mail: eeriotou@yahoo.com; eeriotou@teiion.gr

Received date: September 08, 2015; Accepted date: September 28, 2015; Published date: October 052015

Copyright: @ 2015 Effimia E. This is an open-access article distributed under the terms of the Creative Commons Attribution License, which permits unrestricted use, distribution, and reproduction in any medium, provided the original author and source are credited.

\begin{abstract}
The presence of Listeria monocytogenes and Salmonella spp. was examined in ready-to eat meals, salads, desserts and ice cream in food establishments on the island of Kefalonia, Greece. Samples were collected or delivered from restaurants, canteens, cafes or ice cream parlors. Testing of the presence/absence of the pathogens was performed in $25 \mathrm{~g}$ samples of each product. Of the 1329 samples, 191 (14.4\%) were positive for $L$. monocytogenes and $14(1.05 \%)$ were positive for Salmonella spp. The elevated prevalence of $L$. monocytogenes, especially during the summer months, indicates high risk to consumers of ready-to-eat foods and shows the need for functioning regulatory actions.
\end{abstract}

Keywords: L. monocytogenes, Salmonella spp.; Ready-to-Eat Food; Greece; Survey

\section{Abbreviations:}

RTE: Ready-to-Eat; ISO: International Organization for Standardization; BPW: Buffered Peptone Water; TTn: Tetrathionate; RV: Rappaport-Vassiliadis; XLD: Xylose Lysine Desoxycholate; API: Analytical Profile Index; K-W: Kruskal-Wallis; CDC: Center for Disease Control

\section{Introduction}

Foodborne illnesses represent an extensive, yet largely avertable problem on a global scale. Due to the fact that more and more people regularly eat their meals in public places, while food production and foodstuff commerce are imposing the use of the "cold chain", Listeria monocytogenes is becoming increasingly relevant as emerging pathogen and so are the methods of its restraint, especially in food produced for people that have a high risk of infection. Furthermore, the Center for Disease Control (CDC) estimates that Salmonella spp. is responsible for more than 1.2 million illnesses each year, in the United States [1].

Although the two species are not related, both are of great interest. Salmonella spp. is the leading cause of food infection in the United States and causes the second largest number of human food-borne illnesses in Europe. Listeriosis caused by Listeria monocytogenes is low in incidence but its mortality rate is high placing the microorganism to the top pathogens contributing to food-borne illness resulting in death.

According to a 2010 FoodNet report, rates of infection in the U.S.A. were at least $25 \%$ lower for Listeria than they were a decade ago; Salmonella was only $10 \%$ lower [2]. In Europe, a $10.5 \%$ increase was reported for the year 2012 when compared to 2011 for $L$. monocytogenes. Salmonellosis on the other hand continued to decrease in 2012, with a $4.7 \%$ decrease in confirmed cases compared to 2011 [3]. Although progress has been made in decreasing contamination of some foods and reducing illness caused by some pathogens, more information is needed to understand sources of infection and changes in incidence, and to help determine where to target prevention efforts.

The bacterial genus Listeria currently comprises 10 species, but human cases of listeriosis are almost exclusively caused by the species Listeria monocytogenes. Listeria species are omnipresent organisms that are broadly dispersed in the environment, particularly in plant matter and soil. Listeria monocytogenes is a Gram positive, aerobic to facultative anaerobic, psychrotrophic, non-spore forming bacterium. It is found in foods, water, soil, vegetables, animals and humans $[3,4]$. The principal method of transmission, to both animals and humans, is through ingestion of contaminated food. The bacterium can be found in uncooked nourishments and in processed foods which become contaminated on a post-process level. The temperature range for $L$. monocytogenes is -1 to $45^{\circ} \mathrm{C}$, with the optimal temperature being $30-37^{\circ} \mathrm{C}$. As the bacterium can grow at temperatures below $0^{\circ} \mathrm{C}$, it has the potential to grow in food during refrigerated storage. The fact that this resilient bacterium can multiply at such low temperatures, makes the presence of Listeria in "ready- to-eat" (RTE) foods a fretful trepidation, when one takes into consideration the extended shelf-life of said products. Although the incidence of listeriosis is quite low, the mortality rate of $15.9 \%$ puts this organism among the most significant reasons of death from foodborne illnesses in developed countries [5].

Listeria monocytogenes infection manifestations include mild flulike symptoms (nausea, diarrhea and fever) but there is also the case of invasive listeriosis, where more dire implications are involved (neonatal listeriosis, septicemia, meningitis, meningoencephalitis and less frequently endocarditis). Healthy young persons seldom acquire invasive listeriosis; most listeriosis cases occur in susceptible host populations such as pregnant women, organ transplant recipients, cancer and AIDS patients, individuals with other immunocompromising ailments as well as adults over 65 [6].

The genus Salmonella constitutes of two species: $S$. enterica and $S$. bongori. Salmonellosis in humans is usually described by severe fever, abdominal pain, nausea and sometimes vomiting. Symptoms are often 
Page 2 of 8

minor and most infections are self-limiting, lasting a few days. Nevertheless, in some patients the infection may be more serious and associated with dehydration or septicemia. Mortality is typically low with less than $1 \%$ of reported cases being lethal. The usual reservoir of Salmonella is the intestinal tract of animals from where a variety of foodstuffs of both animal and plant origin may become contaminated with fecal organisms either directly or indirectly. Contamination through food often occurs when organisms are introduced into food preparation areas and are allowed to multiply in food, e.g. due to insufficient storage temperatures, inadequate cooking or crosscontamination of RTE food. Even infected food handlers may act as a cause of contamination for foodstuffs.

The occurrence of both food-borne pathogens has been studied by several groups in several countries. With respect to L. monocytogenes, in China, it has been found that, in RTE foods, the contamination level of Listeria monocytogenes was 6.3-6.9\% [7,8], in Sweden, data from two surveys, performed in 2010, showed that the prevalence of $L$. monocytogenes in some RTE food categories at $\geq 10^{2} \mathrm{cfu} / \mathrm{g}$ was low when meat-product or cheese were tested. This, however, was not the case for fish products and especially gravad (marinated) fish where $12 \%$ of the samples containing $\geq 10^{2} \mathrm{cfu} / \mathrm{g}$ were found [9]. In Turkey [10], in a study of several different salads (samples collected from food presented for sale in the refrigerator) $L$. monocytogenes was found in $6 \%$ of the samples. In Italy, L. monocytogenes was found in only $1.01 \%$ of the RTE samples [11]. In Spain, it was isolated from vegetables at $4.18 \%$ prevalence [12], whereas in Greece it was found at 6.8\% [13] in RTE food in University canteens. In Ethiopia, its prevalence was 5.4\% [14], in products of animal origin. In Portugal a $4.1 \%$ incidence was found for pastry products [15]. In Poland, in cakes and delicatessen (excluding meat products) incidence was $0.4 \%$ and $0.7 \%$ respectively [16].

The most prevalent reports on Salmonella incidence in food include a study in Greece where it was isolated from $17.9 \%$ (13) of the samples in RTE food in University canteens. In China, there are reports of $2-3.5 \%$ of RTE samples positive for Salmonella $[17,18]$ as well as of $39 \%$ positive samples in the Hong Kong area [19]. In Spain, it was detected in $0.7 \%$ of lettuce samples tested [20]. In Nigeria, $S$. typhimurium was detected in $11.1 \%$ of the samples and $S$. typhi in $4.8 \%$ [21]. In Turkey, it was isolated from $8 \%$ RTE salads [10] and from
2.4\% Tulum cheese [22]. In South Africa, it was detected in $16 \%$ of the samples obtained from retail delicatessens [23] and finally, in Egypt, it was detected at $2 \%$ incidence in dairy products [24].

The present study reports the prevalence of the two food pathogens (Salmonella spp. and Listeria monocytogenes) in food samples able to support their growth acquired over a period of two years in RTE foods on the island of Kefalonia, Greece. Care was taken so that the food samples represent all categories of RTE foods which restaurants, canteens and cafes sell as well as both ways that a consumer can obtain the RTE foods i.e. bought from the retail site or delivered. The study examines the prevalence of the two pathogens in a specific highly touristic area of Greece, the island of Kefalonia. It is the third report coming from Greece which differs from the two previous in that it examines food from several different manufacturing establishments as opposed to only food prepared in University restaurants and canteens. Furthermore, Kefalonia is an island on the west sea (Ionian Sea) of Greece, lightly populated, whereas the previous reports took place in the northern part of Greece (in the second highest populated city of Greece). Moreover, it is the first report on seasonal variation of incidence of Salmonella spp. and Listeria monocytogenes in ready-toeat food in Greece.

\section{Materials and Methods}

\section{Food samples}

A total of 1329 food samples were purchased over a period of two years (August 2010 and July 2013) from restaurants, cafes and canteens on the island of Kefalonia, Greece. All food samples were purchased and transferred to the laboratory in sterile and sealed plastic containers or were delivered to the lab through the restaurant's delivery system. Samples bought and transferred to the lab were stored at refrigerated temperature for transportation whereas those delivered were transferred to the lab into the containers used by the restaurant's delivery system. All samples were immediately transported to the laboratory and stored at appropriate refrigeration temperatures. Conditions of the RTE foods at retail level are presented in Table 1. Microbiological analysis was carried out within 1-2 hours of purchase. All samples were tested twice.

\begin{tabular}{|l|l|l|l|}
\hline Food & \multicolumn{2}{l|}{ \# of samples } & Conditions at retail site \\
\hline Meals-1 & \multicolumn{2}{|l|}{} \\
\hline Sandwiches & 103 & Presented for sale in the fridge \\
\hline Cheese and spinach pie & 89 & Kept in electric food warmer at restaurant \\
\hline Cooked meat with vegetables meal & 84 & Kept in electric food warmer at restaurant \\
\hline Total & 276 & \\
\hline Meals-2 & \multicolumn{2}{|l}{} \\
\hline Sandwiches & 97 & Delivered through restaurant's delivery system \\
\hline Cheese and spinach pie & 52 & Delivered through restaurant's delivery system \\
\hline Cooked meat with vegetables meal & 71 & Delivered through restaurant's delivery system \\
\hline Total & $\mathbf{2 2 0}$ & \\
\hline
\end{tabular}




\begin{tabular}{|l|l|l|l|}
\hline Salads-1 & \multicolumn{2}{|l|}{} & Presented for sale in the fridge \\
\hline Vegetables with olive oil & 30 & Presented for sale in the fridge \\
\hline Vegetables with meat and dressing & 53 & \\
\hline Total & \multicolumn{2}{|l|}{} \\
\hline Salads-2 & 27 & Delivered through restaurant's delivery system \\
\hline Vegetables with olive oil & 35 & Delivered through restaurant's delivery system \\
\hline Vegetables with meat and dressing & 62 & \\
\hline Total & \multicolumn{2}{|l|}{} \\
\hline Desserts & 256 & Presented for sale in the fridge \\
\hline Oven baked pastries & 335 & Presented for sale in the fridge \\
\hline Desserts with dairy cream & 591 & \\
\hline Total & 127 & Presented for sale in the freezer \\
\hline Ice cream & 1329 & \\
\hline Grand Total & & \\
\hline
\end{tabular}

Table 1: Food categories and conditions at retail level of RTE foods.

\section{Microbiological analysis}

Salmonella spp. was detected according to ISO 6579:2002/Cor. 1:2004 [25]. Portions of $25 \mathrm{~g}$ from each sample were aseptically transferred in stomacher bags and homogenized with $225 \mathrm{ml}$ of buffered peptone water (BPW) (Difco) for $120 \mathrm{~s}$ using a Stomacher Bag mixer (Interscience). Quantities of 1 and $0.1 \mathrm{ml}$ were inoculated into Tetrathionate (TTn) broth with Novobiocin (Oxoid) and RappaportVassiliadis (RV) broth (Difco), respectively. The enrichment broths were incubated for $24 \pm 2 \mathrm{~h}$ at $37^{\circ} \mathrm{C} \pm 1^{\circ} \mathrm{C}$ (for TTn broth) and $42^{\circ} \mathrm{C}$ (for RV broth), respectively. The positive cultures were streaked onto Xylose Lysine Desoxycholate (XLD) agar (Difco) and Salmonella chromogenic agar (Oxoid) and incubated for $24 \pm 2 \mathrm{~h}$ at $37^{\circ} \mathrm{C} \pm 1^{\circ} \mathrm{C}$. Five presumptive colonies were picked from each plate, inoculated into Triple Sugar agar (Difco) and Lysine Iron agar slopes (Difco) and incubated at $37^{\circ} \mathrm{C} \pm 1^{\circ} \mathrm{C}$ for $24 \pm 2 \mathrm{~h}$. Isolates with typical Salmonella reactions were streaked onto Trypticase Soy agar plates (Difco) and confirmed by the API-20E Enteric Identification System (bioMerieux, Inc.). The reference strains $S$. typhimurium ATCC 25241 and $S$. enteritidis ATCC 49223 were used as positive control strains.

L. monocytogenes was detected according to the ISO 11290-1:1996 [26]. Samples $(25 \mathrm{~g})$ were weighted into sterile stomacher bags and homogenized with $225 \mathrm{ml}$ of Fraser broth (Bio-Rad) for $120 \mathrm{~s}$ using a Stomacher Bag mixer (Interscience). Following the incubation of samples at $37^{\circ} \mathrm{C} \pm 1^{\circ} \mathrm{C}$ for $48 \pm 2 \mathrm{~h}$, positive broths were streaked onto Listeria Palcam agar (Oxoid) and incubated at $37^{\circ} \mathrm{C} \pm 1^{\circ} \mathrm{C}$ for $24 \pm 2 \mathrm{~h}$. Characteristic colonies were streaked onto Trypticase Soy agar plates (Difco) and incubated at $37^{\circ} \mathrm{C} \pm 1^{\circ} \mathrm{C}$ for $24 \pm 2 \mathrm{~h}$. All isolates were Gram stained, tested for motility and catalase activity and identified by the API Listeria system (bioMerieux, Inc.). As positive controls, the $L$. monocytogenes ATCC 19115 and ATCC 7644 strains were used.

Results were expressed as absence or presence of Salmonella spp. or L. monocytogenes per $25 \mathrm{~g}$.

\section{Statistical analysis}

Statistical analysis was carried out by using the SPSS 20.0 software. The aim of the statistical analysis has been to detect differences between the mean percentages of infection incurred by $L$. monocytogenes or Salmonella spp. among the four seasons. Comparisons were made between the mean values of the infection percentages measured during each season over a two year period (2011-2013). A mean value for a specific season was evaluated from 6 individual measurements conducted in the corresponding months during the two year period. Due to the small sample size (6 measurements for each season), non-parametric (or distribution-free) statistical tests were employed. More specifically, the Kruskal-Wallis $(\mathrm{K}-\mathrm{W})$ test was initially applied among the mean values of all four seasons by employing the $95 \%$ significance level. In case the K-W test provided evidence for the existence of statistically significant differences $(p<0.05)$, pairwise comparisons between all four mean values were conducted by using Mann-Whitney tests in order to identify statistically significant differences between two specific mean values.

\section{Results}

A list of all the food samples tested and the prevalence of $L$. monocytogenes for all food categories tested is given in Table 2.

\begin{tabular}{|c|c|c|}
\hline RTE food & L. monocytogenes & Salmonella spp. \\
\hline \multicolumn{3}{|l|}{ Meals-1 } \\
\hline Sandwiches & $20 / 103^{a}(19.4 \%)^{b}$ & $5 / 103(4.9 \%)$ \\
\hline Cheese and spinach pie & $16 / 89(18.0 \%)$ & $1 / 89(1.1 \%)$ \\
\hline $\begin{array}{l}\text { Cooked meat with vegetables } \\
\text { meal }\end{array}$ & $2 / 84(2.4 \%)$ & $0 / 84(0.0 \%)$ \\
\hline
\end{tabular}


Page 4 of 8

\begin{tabular}{|l|l|l|}
\hline Total & 38/276 (13.8\%) & $\mathbf{6 / 2 7 6 ( 2 . 2 \% )}$ \\
\hline Meals-2 & $16 / 97(16.5 \%)$ & $4 / 97(4.1 \%)$ \\
\hline Sandwiches & $10 / 52(19.2 \%)$ & $0 / 52(0.0 \%)$ \\
\hline Cheese and spinach pie & $0 / 71(0.0 \%)$ & $0 / 71(0.0 \%)$ \\
\hline $\begin{array}{l}\text { Cooked meat with vegetables } \\
\text { meal }\end{array}$ & $\mathbf{2 6 / 2 2 0 ( 1 1 . 8 \% )}$ & $\mathbf{4 / 2 2 0 ( 1 . 8 \% )}$ \\
\hline Total & &
\end{tabular}

Salads-1

\begin{tabular}{|l|l|l|}
\hline Vegetables with olive oil & $3 / 23(13.0 \%)$ & $0 / 23(0.0 \%)$ \\
\hline $\begin{array}{l}\text { Vegetables with meat and } \\
\text { dressing }\end{array}$ & $4 / 30(13.3 \%)$ & $1 / 30(3.3 \%)$ \\
\hline Total & $7 / 53(13.2 \%)$ & $1 / 53(1.9 \%)$ \\
\hline
\end{tabular}

Salads-2

\begin{tabular}{|l|l|l|}
\hline Vegetables with olive oil & $3 / 27(11.1 \%)$ & $0 / 27(0.0 \%)$ \\
\hline $\begin{array}{l}\text { Vegetables with meat and } \\
\text { dressing }\end{array}$ & $6 / 35(17.1 \%)$ & $0 / 35(0.0 \%)$ \\
\hline Total & $9 / 62(14.5 \%)$ & $0 / 62(0.0 \%)$ \\
\hline Desserts & $2 / 256(0.8 \%)$ & $0 / 256(0.0 \%)$ \\
\hline Oven baked pastries & $76 / 335(22.7 \%)$ & $3 / 335(0.9 \%)$ \\
\hline Desserts with dairy cream & $78 / 591(13.2 \%)$ & $3 / 591(0.5 \%)$ \\
\hline Total & $33 / 127(26.0 \%)$ & $0 / 127(0.0 \%)$ \\
\hline Ice cream & $191 / 1329(14.4 \%)$ & $14 / 1329(1.05 \%)$ \\
\hline Grand Total &
\end{tabular}

aNumber of positive samples/number of samples analyzed

bercentage of positive samples

Table 2: Prevalence levels of Listeria monocytogenes and Salmonella spp. in RTE foods in Kefalonia, Greece.

\section{Meals bought on site}

Dishes were selected based on what restaurants and canteens usually offer to consumers. It is customary, in Kefalonia, Greece, to have as main meal a dish comprising of meat (beef, pork, goat, sheep or chicken) cooked along with vegetables or a piece of pie which is usually made from fyllo pastrie filled with feta cheese or feta cheese and spinach. Out of the 276 such RTE foods examined, 38 (13.8\%) were contaminated with L. monocytogenes and $6(2.2 \%)$ were tested positive for Salmonella spp., while 2 samples (sandwiches) were contaminated with both pathogens. Of the three RTE food categories examined, the prevalence of $L$. monocytogenes was the highest in sandwiches and pies (cheese and spinach) with 20/103 and $16 / 89$ (or 19.4\% and $18.0 \%$ ) of the samples being positive for the microorganism. In the case of meals composed of cooked meat with vegetables, $L$. monocytogenes was found in $2 / 84(2.4 \%)$ of the samples. In the same RTE foods, Salmonella spp. was found in 6 of the $276(2.2 \%)$ samples tested. Specifically, in the case of sandwiches and pies, Salmonella spp. was found respectively in 5/103 and $1 / 89(4.9 \%$ and $1.1 \%)$ of the samples examined. No cooked meat with vegetable meal was found to be positive for Salmonella spp.

\section{Meals delivered through restaurant's delivery system}

Meals were provided by restaurants only, as canteens do not have a delivery service in Kefalonia, Greece. Out of 220 samples of meals delivered through the restaurant's delivery system 26 (11.8\%) were tested positive for $L$. monocytogenes and $4(1.8 \%)$ were tested positive for Salmonella spp. No sample tested positive for both pathogens. $L$. monocytogenes was detected in 16/97 (16.5\%) and 10/52 (19.2\%) of the samples tested in sandwiches and pies (cheese and spinach) whereas no L. monocytogenes was found in meals composed of cooked meat with vegetables. Salmonella spp. was detected only in sandwiches in $4 / 97$ (4.1\%) of the samples examined.

\section{Salads bought on site}

The traditional Greek salad consists of a variety of vegetables with olive oil and either lemon juice or vinegar as dressing. However, during the last twenty years, salads with other dressings have appeared in restaurants. Frequently, these salads are considered whole meals when pieces of chicken or bacon are incorporated into them. During the examination of the salads that are sold in the restaurants and canteens, care was taken as to include both categories. Fifty three salads were examined and L. monocytogenes was found in 7 (13.2\%) whereas Salmonella spp. was found in $1(1.8 \%)$. No sample tested positive for both microorganisms. When considering the two categories of salads tested, L. monocytogenes was detected in both at $3 / 23(13 \%)$ and $4 / 30$ (13.3\%) in vegetables with olive oil as dressing and vegetables with meat and dressing, respectively. Salmonella was detected only in one sample of vegetables with meat and dressing salad.

\section{Salads delivered through restaurant's delivery system}

In this case, as in the case of meals delivered through restaurant's delivery system, salads were purchased from restaurants only and not canteens. No sample examined showed to be positive for Salmonella. Out of the 62 salads $9(14.5 \%)$ were tested positive for $L$. monocytogenes. L. monocytogenes was detected at 3/27 (11.1\%) and $6 / 35(17.1 \%)$ in vegetables with olive oil as dressing and vegetables with meat and dressing, respectively.

\section{Desserts}

Desserts in Kefalonia, as well as in Greece in general, can be divided into two categories. Those that are prepared and oven baked, where there is no manipulation of the product after receiving the heat treatment and those that include dairy cream filling introduced to the product after the heat treatment. The later often include ingredients such as eggs or their parts which often do not receive enough heat treatment. All desserts were bought on site (restaurants, canteens and cafes) and transferred to the lab. A total of 591 products were examined and L. monocytogenes was found in $78(13.2 \%)$ whereas Salmonella was detected in $3(0.5 \%)$. The three positive for Salmonella spp. samples were also positive for Listeria monocytogenes. The vast majority of $L$. monocytogenes positive samples belonged to the category of desserts with dairy cream as the microorganism was detected in $76 / 335(22.7 \%)$ samples while it was found in only $2 / 256$ $(0.8 \%)$ desserts which are oven baked. Salmonella spp. was detected only in desserts with dairy cream $3 / 335$ (0.9\%). 
Page 5 of 8

\section{Ice cream}

All ice cream samples were bought on site from cafes and ice cream parlors. Out of the 127 samples tested 33 (26.0\%) were found positive for L. monocytogenes and none was found to be positive for Salmonella spp. After contacting the manufacturers, it was known to us that the usual ingredients of ice cream are pasteurized milk and/or dairy cream (in some cases dry milk is used as a substitute), egg and/or egg products, several flavorings, nuts and chocolate.

\section{Seasonal variation}

The monthly distribution of L. monocytogenes and Salmonella spp. on 1329 RTE food samples collected over 24 months in the years 2011-2013 in Kefalonia, Greece is shown in the following (Tables 3 and $4)$.

\begin{tabular}{|c|c|c|c|c|c|c|c|c|c|c|c|c|}
\hline \multirow[t]{2}{*}{ Year } & \multicolumn{3}{|l|}{ Winter } & \multicolumn{3}{|l|}{ Spring } & \multicolumn{3}{|c|}{ Summer } & \multicolumn{3}{|l|}{ Fall } \\
\hline & Dec & Jan & Feb & Mar & Apr & May & Jun & Jul & Aug & Sep & Oct & Nov \\
\hline 2011 & $6 / 55^{a}$ & & & & & & & & $9 / 55$ & $11 / 55$ & $6 / 55$ & $4 / 55$ \\
\hline 2012 & $5 / 55$ & 9/55 & $10 / 55$ & $7 / 55$ & $11 / 55$ & $8 / 55$ & 9/55 & $10 / 55$ & $11 / 55$ & $8 / 55$ & $6 / 56$ & $7 / 56$ \\
\hline 2013 & & $4 / 56$ & $1 / 56$ & $9 / 56$ & $9 / 56$ & 9/56 & $10 / 56$ & $12 / 56$ & & & & \\
\hline Total/month & $11 / 110$ & $13 / 111$ & $11 / 111$ & 16/111 & $20 / 111$ & 17/111 & 19/111 & $22 / 111$ & $20 / 110$ & 19/110 & $12 / 111$ & $11 / 111$ \\
\hline Total/season & \multicolumn{3}{|l|}{$35 / 332$} & \multicolumn{3}{|l|}{$53 / 333$} & \multicolumn{3}{|l|}{$61 / 332$} & \multicolumn{3}{|l|}{$42 / 332$} \\
\hline
\end{tabular}

Table 3: Monthly distributions of L. monocytogenes on 1329 RTE food samples collected over 24 months in the years 2011-2013 in Kefalonia, Greece.

\begin{tabular}{|c|c|c|c|c|c|c|c|c|c|c|c|c|}
\hline & \multicolumn{3}{|c|}{ Winter } & \multicolumn{3}{|c|}{ Spring } & \multicolumn{3}{|c|}{ Summer } & \multicolumn{3}{|l|}{ Fall } \\
\hline & Dec & Jan & Feb & Mar & Apr & May & Jun & Jul & Aug & Sep & Oct & Nov \\
\hline 2011 & $0 / 55^{a}$ & & & & & & & & $1 / 55$ & $0 / 55$ & $0 / 55$ & $0 / 55$ \\
\hline 2012 & $0 / 55$ & $0 / 55$ & $1 / 55$ & $0 / 55$ & $1 / 55$ & $2 / 55$ & $2 / 55$ & $2 / 55$ & $1 / 55$ & $1 / 55$ & $0 / 56$ & $1 / 56$ \\
\hline 2013 & & $0 / 56$ & $0 / 56$ & $0 / 56$ & $0 / 56$ & $1 / 56$ & $1 / 56$ & 0/56 & & & & \\
\hline Total/month & $0 / 110$ & 0/111 & $1 / 111$ & 0/111 & $1 / 111$ & $3 / 111$ & $3 / 111$ & $2 / 111$ & $2 / 110$ & $1 / 110$ & 0/111 & $1 / 111$ \\
\hline Total/season & \multicolumn{3}{|l|}{$1 / 332$} & \multicolumn{3}{|l|}{$4 / 333$} & \multicolumn{3}{|l|}{ 7/332 } & \multicolumn{3}{|l|}{$2 / 332$} \\
\hline
\end{tabular}

Table 4: Monthly distributions of Salmonella spp. on 1329 RTE food samples collected over 24 months in the years 2011-2013 in Kefalonia, Greece.

The results of the statistical analysis are given below, separately for each microorganism.

L. monocytogenes: By applying the Kruskal-Walis test among the mean percentages of incidence observed in all four seasons a $\mathrm{p}$ value of 0.027 (i.e. $<0.05$ ) was obtained, thus providing evidence for the existence of statistically significant differences. Subsequent application of pairwise Mann-Whitney tests showed that the mean percentages of contamination incurred by $L$. monocytogenes in the Summer was higher than the ones in Winter, Spring and Fall at 95\% statistical significance. On the other hand, no statistically significant differences were detected between the mean percentages of contamination observed in Winter, Spring and Fall.

Salmonella spp.: By applying the Kruskal-Walis test among the mean percentages of infection observed in all four seasons a $p$ value of 0.096 (i.e. $>0.05$ ) was obtained, thus providing evidence for the absence of statistically significant differences between them.

\section{Discussion}

To date, limited information has been available on the prevalence of L. monocytogenes and Salmonella spp. in RTE food in Greece, and to our knowledge, no such study has been reported for the island of Kefalonia yet. Our results show the prevalence of $L$. monocytogenes and Salmonella spp. in the most common RTE foods sold in the food establishments of Kefalonia in the two year period between August 2011 and July 2013. A total of 1329 samples were examined. L. monocytogenes was found in 191 whereas Salmonella was found in 14 of the samples.

With respect to L. monocytogenes, it was found that $13.8 \%$ and $11.8 \%$ of the samples of meals (presented for sale in the fridge and delivered through restaurants delivery system, respectively) examined were contaminated with the microorganism. However, its incidence in cooked meat and vegetable meals was low $(2.4 \%$ and $0 \%$ in meals presented for sale in the fridge and delivered through restaurants 
delivery system, respectively), whereas it was high in the other two categories of meals examined. In the case of sandwiches, contamination was observed in $19.4 \%$ and $16.5 \%$ of the sandwiches examined (presented for sale in the fridge and delivered through restaurants delivery system, respectively). Two reports from Greece have recorded $7.7 \%$ and $7.3 \%$ prevalence of the microorganism in sandwiches examined in Northern Greece [13,27]. The ingredients of specific products examined in our study were bread, cheese, meat product, tomato, salad greens and dressing. L. monocytogenes contamination has been previously related partially to cheese, ham, vegetables, mayonnaise and mayonnaise salad constituting the sandwiches [27]. As the use of organic vegetables is a preferred practice in the island, the much higher contamination observed may be attributed partly to that practice. Occurrence of L. monocytogenes in cheese and spinach pie was also very high (18\% and $19.2 \%$ in the products presented for sale in the fridge and delivered through restaurants delivery system, respectively). In the case of these products, they are usually produced by specific companies, frozen and transported in this condition to the restaurants, canteens or any other retail store. The places that serve these foods, bake them usually while in the frozen state and serve them. The major problem in this kind of handling is that it does not ensure that the combination of time and temperature used to cook the product is enough to kill all pathogens present in the frozen food.

The incidence of L. monocytogenes in the samples of salads examined was high $(13.2 \%$ and $14.5 \%$ in the salads presented for sale in the fridge and delivered through restaurants delivery system, respectively). Ingredients in all salads examined, in this study, were salad greens, tomato, cucumbers. Furthermore, some of the salads included some kind of meat (chicken or bacon). The dressing used in salads with vegetables only constituted from olive oil and vinegar or lemon juice whereas the salads with meat had a mayonnaise base dressing. Although some of the L. monocytogenes load can be attributed to the presence of meat in the salad, equally important if not more, is the load found on raw vegetables. As has already been mentioned, organic vegetables are preferred in the island and usually carry a heavy bacterial load. Results on incidence of the microorganism in salads from reports from other countries vary. A report from Turkey has recorded a $13.4 \%$ contamination with $L$. monocytogenes in Caesar salad (a salad composed of boiled or fried chicken, fried bread, lettuce, parsley, tomato, cucumber and boiled corn) [10], results that agree with ours. Jamali et al. [28] found that, in Malaysia, the high prevalence of L. monocytogenes was distributed in salads and vegetables. In South China, $26.7 \%$ of the cold vegetables dishes in sauce were found to be contaminated [7]. No $L$. monocytogenes was detected in RTE salads in Italy [29].

Out of all food categories examined, the presence of $L$. monocytogenes was the highest in desserts with dairy cream and ice cream ( $22.7 \%$ and $26 \%$, respectively), both of which are predominantly made with whipped cream or with pastry cream both of which involve much handling throughout the final formulation process. Another factor is the omnipresence of uncooked eggs throughout kitchen working stations since the pasteurized liquid/powdered egg option is not favored. This fact, escalated by the occasional addition of raw eggs in the final preparatory stages, leads to cross-contamination of RTE desserts and ice cream. Kotzekidou [13] reported a high prevalence rate of $20 \%$ in desserts with dairy cream and a $17.7 \%$ in desserts [27] in studies in Northern Greece.
Different criteria or recommendations for L. monocytogenes have been established in RTE foods in different countries. In the USA and Italy, a zero tolerance policy has been adopted in RTE foods. In other EU countries (i.e. Germany, Netherlands, France and Greece), there is a tolerance of bellow $10^{2} \mathrm{cfu} / \mathrm{g}$ of food at the time of consumption [30, 31 ]. As already mentioned $L$. monocytogenes can grow at refrigeration temperatures and most of these products use refrigeration as the sole method to control pathogen growth.

Salmonella spp. contamination was lower than that observed for $L$. monocytogenes. The highest incidence of Salmonella spp., was found in meals $6 / 276$ and $4 / 220(2.2 \%$ and $1.8 \%)$ of the meals presented for sale in the fridge and delivered through restaurants delivery system, respectively. Out of the ten positive samples for Salmonella nine belonged to the sandwich category. These data show a lower incidence than that found in previous studies in Northern Greece [13] and South Africa [23] where $17.5 \%$ and $20 \%$ of the sandwiches tested were found to be contaminated with Salmonella spp. The other sample positive for Salmonella was a cheese pie. Results from a previous Greek study show a $13.7 \%$ contamination level in oven baked pastries [13], results which are substantially higher than ours. In the salads category $1 / 115(0.1 \%)$ was found positive for the pathogen. The specific salad consisted of raw vegetables, chicken and mayonnaise-base dressing. Incidence of Salmonella spp. in salads has been studied in Spain, South Africa, Turkey, Nigeria with $0.7 \%, 11 \%, 8.0 \%$ and $8.0 \%$ [10,20,21,23], respectively, being positive for the bacterium.

Desserts with dairy cream had the second highest incidence of Salmonella, with $3 / 335$ ( $0.9 \%)$ of the samples tested being positive. This result is much lower than what was detected in a study in Northern Greece [13] where a $12.5 \%$ incidence of the pathogen was found in the specific food group. The overall Salmonella spp. positive samples were $14 / 1329$ (1.05\%). No Salmonella was detected in cooked meat with vegetables meals, vegetables with olive oil (salads) or ice cream, indicating proper procedures during preparation, handling and storage of these food items.

With regard to the dependence of the frequency of contamination on the time of the year, the results of our study indicate a statistically significant higher presence of $L$. monocytogenes during summer. On the other hand, our experimental data did not provide strong evidence for the existence of the same dependence for Salmonella spp. These findings are consistent with those published by EFSA [3] for $L$. monocytogenes reported cases for the European Union. A similar periodic incidence was reported for Salmonella spp. as well [3]. The observed very low contamination frequencies in combination with the small number of data (6 measurements) are the most probable causes for the failure of our statistical analysis to detect statistically significant differences between the different times of the year for Salmonella spp.

Results showed that RTE foods can be contaminated with $L$. monocytogenes and Salmonella spp. The high prevalence of $L$. monocytogenes in many of the RTE foods examined (sandwiches, cheese and spinach pie, salads, desserts with dairy cream and ice cream) shows that there is a need for improved in-house control to reduce risks of human listeriosis, as the most probable sources of contamination include contaminated raw material and post-processing contamination, even though the possibility that the cooking process is not sufficient in some cases, cannot be ruled out.

A major issue in the island of Kefalonia is the preference shown by the consumers for organically grown food. Indeed, consumer concern over the quality and safety of food has intensified in recent years 
resulting in a rise in the demand of organically grown food. Hence, from a marketing point of view, RTE products appear to be more attractive to consumers when organic ingredients and few or no additives are used. Furthermore, the use of sanitizers in organic fresh produce is strictly regulated, resulting in very low concentrations of such compounds and thus raising sanitation questions [32]. Essential oils, which have been extensively studied, could constitute an effective and legal solution to this difficulty and become an alternative for synthetic preservatives [32-34].

\section{Conclusions}

In conclusion, this study revealed a low incidence of Salmonella in RTE foods sold in restaurants, canteens and cafes in the island of Kefalonia. However, the prevalence of L. monocytogenes, in the same food samples was high indicating high risk to consumers as RTE foods are consumed directly after purchase without any further treatment to reduce the microbial load. The island is in need not only of legal and appropriate manufacturing practices but also of intensified hygiene inspections pertaining to foodstuff. Additionally, operative control actions should be employed in order to develop a higher microbiological quality of RTE foods. Such actions could potentially be systematizing workshops, instructive seminars or conferences on food handling and hygiene practices for all involved parties of RTE food production.

\section{References}

1. Anonymous (2014) Salmonella data now at your fingerprints. Centers for Control Disease and Prevention.

2. Anonymous (2014) CDC estimates of foodborne illness in the United States. Centers for Control Disease and Prevention.

3. EFSA (European Food Safety Authority) and ECDC (European Center for Disease Prevention and Control) (2014) The European Union Summary Report on Trends and Sources of Zoonoses, Zoonotic agents and food-borne outbreaks in 2012. EFSA Journal 12: 3547.

4. Cocolin L, Stella S, Nappi R, Bozzetta E, Cantoni C, et al. (2005) Analysis of PCR-based methods for characterization of Listeria monocytogenes strains isolated from different sources. Int J Food Microbiol 103: 167-178.

5. Scallan E, Hoekstra RM, Angulo FJ, Tauxe RV, Widdowson MA, et al. (2011) Foodborne illness acquired in the United States-Major pathogens. Emerg Infect Dis 17: 7-15.

6. Chan YC, Wiedmann M (2009) Physiology and genetics of Listeria monocytogenes survival and growth at cold temperatures. Crit Rev Food Sci Nutr 49: 237-253.

7. Chen M, Qingping W, Zhang J, Yan Z, Wang J (2014) Prevalence and characterization of Listeria monocytogenes isolated from retail-level ready-to-eat foods in South China. Food Control 38: 1-7.

8. Shi W, Qingping W, Jumei Z, Moutong C, Zean Y (2015) Prevalence, antibiotic resistance and genetic diversity of Listeria monocytogenes isolated from retail ready-to-eat foods in China. Food Control 47: 340-347.

9. Lambertz ST, Nilsson C, Bradenmark A, Sylven S, Johansson A, et al. (2012) Prevalence and level of Listeria monocytogenes in ready-to-eat foods in Sweden 2010. Int J Food Microbiol. 160: 24-31.

10. Gurler Z, Pamuk S, Yildirim Y, Ertas N (2015) The microbiological quality of ready-to-eat salads in Turkey: A focus on Salmonella spp. and Listeria monocytogenes. Int J Food Microbiol 196: 79-83.

11. Pesavento G, Ducci B, Nieri D, Comodo N, Nostro AL (2010) Prevalence and antibiotic susceptibility of Listeria spp. isolated from raw meat and retail foods. Food Control 21: 708-713.

12. Moreno Y, Sanchez-Contreras J, Montes RM, Garcia-Hernandez J, Ballesteros L, et al. (2012) Detection and enumeration of viable Listeria monocytogenes cells from ready-to-eat and processed vegetable foods by culture and DVC-FISH. Food Control 27: 374-379.

13. Kotzekidou P (2013) Microbiological examination of ready-to-eat foods and ready-to-bake frozen pastries from university canteens (2013) Food Microbiol 34: 337-343.

14. Gebretsadik S, Kassa T, Alemayehu H, Huruy K, Kebede N (2011) Isolation and characterization of Listeria monocytogenes and other Listeria species in foods of animal origin in Addis Ababa, Ethiopia. J Infect Public Health 4: 22-29.

15. Mena C, Almeida G, Carneiro L, Teixeira P, Hogg T, et al. (2004) Incidence of Listeria monocytogenes in different food products commercialized in Portugal. Food Microbiol 21: 213-216.

16. Maćkiw E, Modzelewska M, Mąka L, Ścieżyńska H, Pawłowska K, et al. (2016) Antimicrobial resistance profiles of Listeria monocytogenes isolated from ready-to-eat products in Poland in 2007-2011. Food Control 59: 7-11.

17. Yu Q, Zhai L, Bie X, Lu Z, Zhang C, et al. (2016) Survey of five foodborne pathogens in commercial cold food dishes and their detection by multiplex PCR. Food Control. 59: 862-869.

18. Yang X, Huang J, Wu Q, Zhang J, Liu S, et al. (2016) Prevalence, antimicrobial resistance and genetic diversity of Salmonella isolated from retail ready-to-eat foods in China. Food Control 60: 50-56.

19. Ng YF, Wong SL, Cheng HL, Yu PHF, Chan SW (2013) The microbiological quality of ready-to-eat food in Siu Mei and Lo Mei shops in Hong Kong. Food Control 34: 547-553.

20. Sospedra I, Rubert J, Soriano JM, Manes J (2013) Survey of microbial quality of plant-based foods served in restaurants. Food Control 30: 418-422.

21. Isara AR, Isah EC, Lofor PV, Ojide CK (2010) Food contamination in fast food restaurants in Benin City, Edo State, Nigeria: Implications for food hygiene and safety. Public Health 124: 467-471.

22. Colak H, Hampikyan H, Bingol EB, Ulusoy B (2007) Prevalence of $L$. monocytogenes and Salmonella spp. in Tulum cheese. Food Control 18: 576-579.

23. Christison CA, Lindsay D, von Holy A (2008) Microbiological survey of ready-to-eat foods and associated preparation surfaces in retail delicatessens, Johannesburg, South Africa. Food Control 19: 727-733.

24. Ahmed AM, Shimamoto $\mathrm{T}$ (2014) Isolation and molecular characterization of Salmonella enterica, Escherichia coli O157:H7 and Shigella spp. from meat and dairy products in Egypt. Int J Food Microbiol 168-169: 57-62.

25. ISO (2002) Microbiology of Food and Animal Feeding Stuffs-Horizontal Method for the Detection of Salmonella spp. (6579:2002). International Organization for Standardization, Geneva.

26. ISO (1996) Microbiology of Food and Animal Feeding Stuffs-Horizontal Method for the Detection and Enumeration of Listeria monocytogenes. Part 1: Detection Method (11290-1:1996). International Organization for Standardization, Geneva.

27. Kotzekidou P (2013) Survey of Listeria monocytogenes, Salmonella spp. and Escherichia coli $\mathrm{O} 157: \mathrm{H} 7$ in raw ingredients and ready-to-eat products by commercial real-time PCR kits. Food Microbiol 35: 86-91.

28. Jamali H, Chai LC, Thong KL (2013) Detection and isolation of Listeria spp. and Listeria monocytogenes in ready-to-eat foods with various selective culture media. Food Control 32: 19-24.

29. Caponigro V, Ventura M, Chiancone I, Amato L, Parente E, et al. (2010) Variation of microbial load and visual quality of ready-to-eat salads by vegetable type, season, processor and retailer. Food Microbiol 27: 1071-1077.

30. European Commission (2005) Regulation (EC) No 2073/2005 of 15 November 2005 on microbiological criteria for foodstuffs. Official Journal of European Union L 338: 1-26.

31. European Commission (2007) Commission Regulation (EC) No 1441/2007 of 5 December 2007 amending Regulation (EC) No 2073/2005 on microbiological criteria for foodstuffs. Official Journal of European Union L 332: 12-29. 
Citation: Effimia E (2015) Prevalence of Listeria monocytogenes and Salmonella spp. in Ready-to-Eat Foods in Kefalonia, Greece. J Bacteriol Parasitol 6: 243. doi:10.4172/2155-9597.1000243

Page 8 of 8

32. Davidson PM, Critzer FJ, Taylor TM (2013) Naturally occurring antimicrobials for minimally processed foods. Annu Rev Food Sci Technol 4: 163-190.

33. Eriotou E, Anastasiadou K, Nikolopoulos D, Koulougliotis D (2015) Antimicrobial and free radical scavenging activities of basil (Ocimum basilicum) essential oil isolated from five plant varieties growing in Greece. J Nutr Food Sci 5: 3.

34. Panagou EZ, Nychas GJE, Sofos Jn (2013) Types of traditional Greek foods and their safety. Food Control 29: 32-41. 